\title{
Height and wavelength of alternate bars in rivers: modelling vs. laboratory experi- ments
}

\section{Hauteur et longueur d'onde des bancs alternés en rivières : la modélisation face aux expériences de laboratoire}

\author{
M.A.F. KNAAPEN, Dep. of Civil Engineering, University of Twente, P.O. Box 217, 7500 AE Enschede, The Netherlands. \\ S.J.M.H. HULSCHER, Dep. of Civil Engineering, University of Twente, P.O. Box 217, 7500 AE Enschede, The Netherlands. \\ H.J. DE VRIEND, Dep. of Civil Engineering, University of Twente, P.O. Box 217, 7500 AE Enschede, The Netherlands.
}

A. VAN HARTEN, Dep. of Management Studies, University of Twente, P.O. Box 217, 7500 AE Enschede, The Netherlands.

\begin{abstract}
Alternate bars are large wave patterns in sandy beds of rivers and channels. The crests and troughs alternate between the banks of the channel. These bars, which move downstream several meters per day, reduce the navigability of the river. Recent modelling of alternate bars has focused on stability analysis techniques. We think, that the resulting models can predict large rhythmic patterns in sandy beds, especially if the models can be combined with data-assimilation techniques. The results presented in this paper confirm this thought.

We compared the wavelength and height of alternate bars as predicted by the model of Schielen et al. [14], with the values measured in several flume experiments. Given realistic hydraulic conditions $R \sqrt{R e}>2 * 10^{3}$, ( $R$ the width-to-depth ratio and $R_{e}$ the Reynolds number), the predictions are in good agreement with the measurements. In addition, the model predicts the bars measured in experiments with graded sediment. If $R \sqrt{R e}<2 * 10^{3}$, the agreement between model results and measurements is lost. The wave height is clearly underestimated, and the standard deviation of the differences between predictions and measurements increases. This questions the usefulness of small flume experiments for morphodynamic problems.
\end{abstract}

\section{RÉSUMÉ}

Les bancs alternés sont des configurations de grandes ondulations dans les fonds sablonneux des rivières et des chenaux. Les crêtes et les creux alternent entre les rives du chenal. Ces bancs, qui se déplacent vers l'aval de plusieurs mètres par jour, réduisent la navigabilité de la rivière. La modélisation récente des bancs alternés s'est concentrées sur les techniques d'analyse de stabilité. Nous pensons que les modèles résultant peuvent prédire les grandes configurations régulières dans les lits sablonneux, notamment si les modèles peuvent être combinés à des techniques intégrant des données. Les résultats présentés dans l'article confirment cette idée. Nous avons comparé la longueur d'onde et la hauteur des bancs alternés prédites par le modèle de Schielen et al., avec les valeurs mesurées dans plusieurs expériences en canal. Des conditions hydrauliques réalistes étant données, $R \sqrt{R e}>2.10^{3}(R$ étant le rapport de la largeur à la profondeur, et $R_{e}$ le nombre de Reynolds), les prédictions sont en bon accord avec les mesures. En outre, le modèle prévoit les bancs mesurés dans les expériences avec des sédiments calibrés. Si $R \sqrt{R e}<2.10^{3}$, on perd l'accord entre les résultats du modèle et les mesures. La hauteur des ondulations est nettement sous-estimée et l'écart-type des différences entre prévisions et mesures augmente. Ceci remet en cause l'utilité des expériences à petites échelles pour les problèmes de morphodynamique.

\section{Introduction}

The interaction between a non-cohesive bed and the water flowing over it results in interesting phenomena. Several types of wave patterns can be seen on the bed, each caused by a different process. The largest bedform observed in fixed-bank rivers and channels is termed alternate bar. Alternate bars are wave patterns, of which the crest and trough alternate between the banks of the channel (see Figure 1). These bars move downstream at a speed of several meters per day. Their existence reduces the navigability and influences the water capacity of the channel. Therefore, it is important to predict the behaviour of these bars.

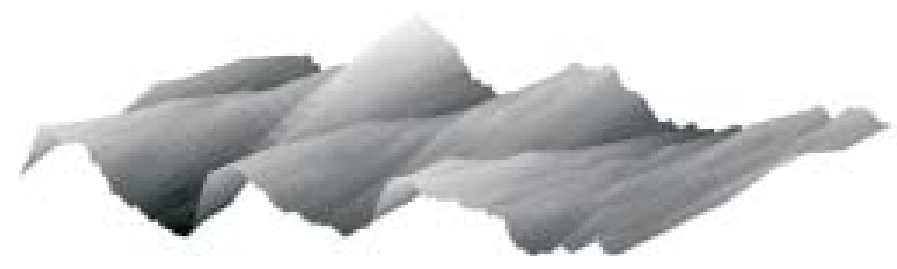

Fig. 1. Alternate bars in a channel as measured in a straight laboratory flume Lanzoni [9]. The crests alternate between the side banks. (The flow is from right to left.)
The existence of alternate bars is thought to be an inherent instability of the bed-flow system. Therefore, state of the art research into modelling of alternate bars has focused on stability analysis techniques [2][3][4][14][16][18]. Both Colombini et al. [4] and Schielen et al. [14] formulate a weakly non-linear model, which allows for small temporal variations of the amplitudes of the bars. Only the latter model also allows for slow spatial variation. Colombini and Tubino [3] developed a fully non-linear model. The model of Schielen et al. [14] describes behaviour, similar to the behaviour of alternate bars in rivers. However, to predict using their model, more lengthy and error-prone mathematical derivations are necessary. Data-assimilation techniques [5] may be the solution to avoid these derivations. Further, these techniques can generalise the results to other large rhythmic bed waves, like sand waves and shore parallel bars in the sea. As a start, such an approach requires the model to estimate the characteristics of the patterns correctly.

So far, the models have hardly been tested against either field or laboratory data. Schielen et al. [14] used their model for a qualitative analysis of the phenomenon only. Colombini et al. [4] compared the results of their model with data from small-scale experiments, in which the width of the flume never exceeded $0.7 \mathrm{~m}$. 
The differences between their model results and the measurements were imputed on the scale effects due to this small channel width. Recently, Lanzoni [9][10] performed morphological laboratory experiments in a flume of $1.5 \mathrm{~m}$ wide, $1 \mathrm{~m}$ deep and $50 \mathrm{~m}$ long. The experiments in this flume, and therefore the results are assumed more realistic.

In this paper, the wavelength and height of alternate bars as predicted by the model of Schielen et al. [14] are compared with the length and height of alternate bars measured in several flume experiments. The large flume experiments of Lanzoni [9][10] are included in this comparison. The comparison leads to an assessment of the validity of using a weakly non-linear stability analysis to predict alternate bar behaviour.

\section{Available results of laboratory experiments}

The available data of experiments can be divided in 2 groups. The first group consists of experiments carried out by Lanzoni [9][10]. These experiments are well documented. The second group consists of experiments by several researchers [1][6][7][12][17]. Only little information on these experiments is available to the authors. However, this group is much larger then the first one.

\subsection{Lanzoni's experiments}

In the large straight sand flume of Delft Hydraulics, Lanzoni [9][10] generated alternate bars, using steady flow conditions. The flume is $1.5 \mathrm{~m}$ wide, $1 \mathrm{~m}$ deep and $50 \mathrm{~m}$ long. The bathymetry can be measured over $43.8 \mathrm{~m}$. During the experiments, all flow characteristics were controlled. Both the water depth and the flow velocity were held constant at the required values. The sand leaving the flume was weighed and subsequently fed back at the upstream end of the flume, evenly spread over the width. The experiments were divided into two series. In the first series the sediment was uniform $\left(d_{50}=481 \mu \mathrm{m}, d_{90}=710\right.$ $\left.\mu \mathrm{m}, \rho_{\mathrm{s}}=2.65 \mathrm{~g} / \mathrm{cm}^{3}\right)$. In the second series graded sediment was used $\left(d_{50}=262 \mu \mathrm{m}, d_{90}=3210 \mu \mathrm{m}, \rho_{\mathrm{s}}=2.65 \mathrm{~g} / \mathrm{cm}^{3}\right)$. Table 1 summarises the conditions of the experiments using both uniform and graded sediment.

A water-level indicator and a profile indicator measure the water level and the bed profile respectively. In bursts of 4 to 6 minutes, these measurements were taken over three longitudinal sections, one in the middle and the other two at $0.20 \mathrm{~m}$ from each bank. The interval between two successive measurements depended on the bed form celerity. At the end of an experiment, more measurements of the bathymetry were performed at 0.40 and 0.60 meter from each wall. The sediment transport rate was determined from the immersed weight of the sediment collected at the end of the flume. The Chezy coefficient was estimated from the measured water depth using:

$$
C_{z}=\frac{u}{\sqrt{h_{*} i_{b}}}
$$

where $h_{*}$ is the average bottom depth, $i_{b}$ is the bed slope, and $u$ is the average flow velocity.

The measurements of the water level and the bed level can be used to determine the water depth: $h_{*}=\zeta-z_{b}$, in which $z_{b}$ and $\zeta$ are the bed-level and the water level, respectively. Figure 2 shows an example of three resulting longitudinal bed profiles.

For each section, the average longitudinal bed slope $\left(i_{b 1}, i_{b 2}\right.$ and $\left.i_{b 3}\right)$ is calculated using linear regression. The noise, caused by

Table 1 Conditions and results of experiments on alternate bars by Lanzoni [9][10]. Here $T$ gives the duration of the experiment, $Q$ the average water flux, $i_{b}$ the longitudinal water surface slope, $h_{*}$ the average water depth, $u$ the average flow velocity, $C_{z}$ the Chezy coefficient and $F r$ the Froude number. $L_{b}$ and $H_{b}$ are the length and the height of the bars respectively

\begin{tabular}{|l|r|r|r|r|r|r|r|r|r|}
\hline run & $\begin{array}{r}\mathrm{T} \\
{[\mathrm{h}]}\end{array}$ & $\begin{array}{r}\mathrm{Q} \\
{\left[\mathrm{m}^{3} / \mathrm{s}\right]}\end{array}$ & $\begin{array}{r}\mathrm{i}_{\mathrm{b}} \\
{[\%]}\end{array}$ & $\begin{array}{r}\mathrm{h}_{*} \\
{[\mathrm{~cm}]}\end{array}$ & $\begin{array}{r}\mathrm{u} \\
{[\mathrm{m} / \mathrm{s}]}\end{array}$ & $\begin{array}{r}\mathrm{C}_{2} \\
{\left[\mathrm{~m}^{1 / 2} / \mathrm{s}\right]}\end{array}$ & $\begin{array}{r}\mathrm{F}_{\mathrm{r}} \\
{[-]}\end{array}$ & $\begin{array}{r}\mathrm{L}_{\mathrm{b}} \\
{[\mathrm{m}]}\end{array}$ & $\begin{array}{r}\mathrm{H}_{\mathrm{b}} \\
{[\mathrm{cm}]}\end{array}$ \\
\hline uniform & & & & & & & & & \\
sediment & & & & & & & & & \\
\hline P1801 & 816 & 0.03 & 0.16 & 7.3 & 0.27 & 25.2 & 0.32 & 11.3 & 8.5 \\
P2403 & 260 & 0.047 & 0.21 & 8.3 & 0.38 & 28.9 & 0.42 & $4.5-7.5$ & $5.0-6.0$ \\
P0404 & 192 & 0.04 & 0.2 & 7.7 & 0.35 & 27.8 & 0.4 & $4.3-8.0$ & 6.0 \\
P1505 & 28 & 0.03 & 0.45 & 4.4 & 0.45 & 32.2 & 0.69 & 10 & 7.0 \\
P1605 & 24 & 0.02 & 0.5 & 3.3 & 0.4 & 31.6 & 0.71 & 11 & 7.7 \\
P2709 & 24 & 0.045 & 0.51 & 5.7 & 0.53 & 30.7 & 0.7 & 9.7 & 4.5 \\
P2809 & 24 & 0.04 & 0.52 & 5.3 & 0.5 & 30.4 & 0.7 & 10.6 & 4.7 \\
P2909 & 24 & 0.045 & 0.52 & 5.6 & 0.53 & 31.3 & 0.72 & 9.5 & 4.4 \\
\hline graded & & & & & & & & & \\
sediment & & & & & & & & & \\
\hline P0807 & 73 & 0.03 & 0.42 & 0.043 & 0.47 & 34.7 & 0.71 & 10.4 & 0.042 \\
P0109 & 51 & 0.04 & 0.51 & 0.047 & 0.57 & 36.1 & 0.83 & 11.7 & 0.04 \\
P1309 & 29 & 0.045 & 0.53 & 0.05 & 0.6 & 36.7 & 0.85 & 10.3 & 0.034 \\
P2009 & 3 & 0.045 & 0.53 & 0.058 & 0.6 & 36.6 & 0.85 & 10.2 & 0.034 \\
\hline
\end{tabular}


small-scale ripples and dunes, is filtered out of the bottom profiles, using the moving-frame averaging method [13]. (The size and shape of the windows is unknown.) Finally, the large-scale bar characteristics are estimated. The bar height is defined as the difference between the maximum and the minimum bed elevation, within a bar unit. Note that the filtering of the measurements results in low estimates of the bar height, since it reduces the extremes. The bar length is estimated using a spectral analysis [13] of the filtered bottom profile Figure 2 shows that only a few large-scale bars exist in the flume. Therefore, the accuracy of the height and length estimates of the bars is limited. Table 1 presents the characteristics of the observed alternate bars.

\subsection{Small scale experiments by others}

In the past, several small-scale flume experiments were carried out. Here the experimental results of Ashida [1], Jaeggi [6], Kinoshita [7], Muramoto [12], Sukegawa [17] are relevant. In these experiments, the width of their flumes varied from 13 to 55 $\mathrm{cm}$. In the experiments, the water depth, the surface slope, and the flow velocity were measured. The information of the sediment used is limited: only the mean diameter and the density characterise the sediment. Table 2 summarises the conditions under which these experiments were run.

\section{The amplitude evolution model of Schielen et al. [14]}

\subsection{Basic equations}

To describe the behaviour of alternate bars in rivers, the morphodynamic model of Schielen et al. [14], which is an extension of Colombini et al. [4], will be used. The model of Schielen et al. [14] is discussed briefly below.

Schielen et al. [14] considered a uniform, shallow-water flow in a straight, infinitely long channel, with a uniform, mild slope: $i_{b}$
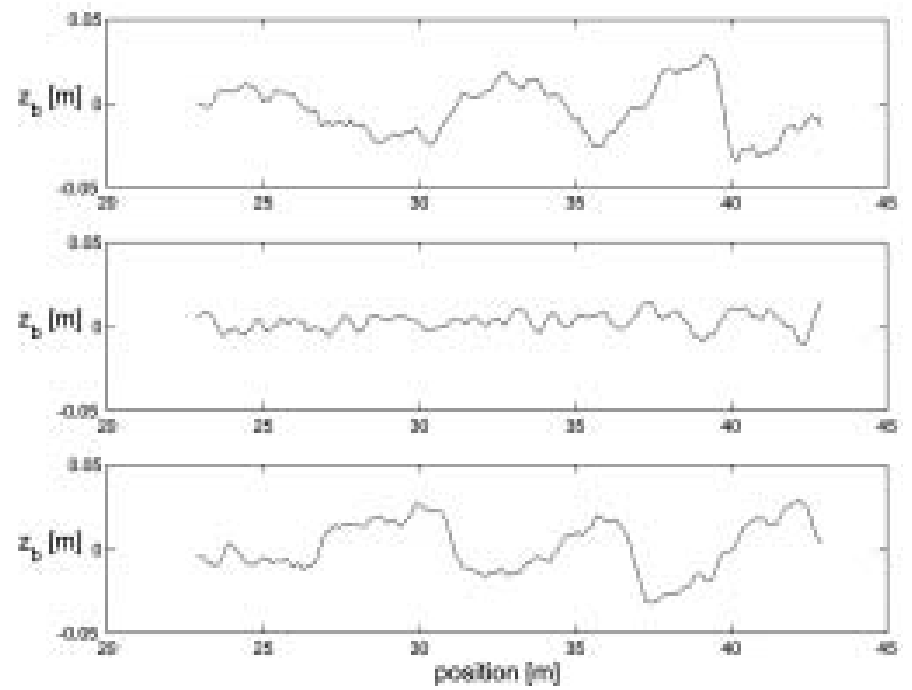

Fig. 2. Longitudinal bed profile measured during experiment P1801. Top down is subsequently shown: the profiles along a section near the left bank, in the middle and near the right bank of the flume.
Table 2 Conditions during several small-scale flume experiments. Here $y_{*}$ is the width of the flume, \# is the number of experiments, with the range of the flow velocity and the water depth given by $u$ and $h_{*}$, respectively. $d_{s}$ and $\rho_{s}$ are the size and the density of the sediment, respectively.

\begin{tabular}{|l|r|r|r|r|r|r|}
\hline Name & $\begin{array}{r}\mathrm{y}_{*} \\
{[\mathrm{~m}]}\end{array}$ & $\begin{array}{r}\# \\
{[-]}\end{array}$ & $\begin{array}{r}\mathrm{d}_{\mathrm{s}} \\
{[\mathrm{mm}]}\end{array}$ & $\begin{array}{r}\rho_{\mathrm{s}} \\
{\left[\mathrm{g} / \mathrm{cm}^{3}\right]}\end{array}$ & $\begin{array}{r}\mathrm{u} \\
{[\mathrm{m} / \mathrm{s}]}\end{array}$ & $\begin{array}{r}\mathrm{h}_{*} \\
{[\mathrm{~cm}]}\end{array}$ \\
\hline Ashida & 0.5 & 13 & 1 & 2.65 & $0.30-0.50$ & $2.0-3.5$ \\
\hline Jaeggi & 0.3 & 13 & 0.52 & 2.65 & $0.25-0.50$ & $1.6-2.8$ \\
& 0.3 & 23 & 3 & 1.45 & $0.15-0.40$ & $1.6-4.1$ \\
& 0.3 & 11 & 1.8 & 2.65 & $0.35-0.50$ & $1.4-4.1$ \\
& 0.3 & 1 & 4 & 2.65 & 0.37 & 2.44 \\
\hline Kinoshita & 0.132 & 4 & 0.38 & 2.65 & \pm 0.30 & $0.8-1.1$ \\
& 0.132 & 3 & 0.76 & 2.65 & $0.35-0.45$ & $0.6-1.2$ \\
& 0.132 & 14 & 1.24 & 2.65 & $0.30-0.50$ & $0.4-1.2$ \\
& 0.132 & 5 & 1.7 & 2.65 & $0.30-0.50$ & $0.7-1.7$ \\
\hline Muramoto & 0.55 & 8 & 0.99 & 2.65 & $0.35-0.75$ & $2.1-4.5$ \\
& 0.25 & 3 & 0.99 & 2.65 & $0.35-0.60$ & $1.3-2.0$ \\
\hline Sukegawa & 0.15 & 5 & 2.3 & 2.65 & $0.40-0.60$ & $0.6-1.9$ \\
& 0.15 & 6 & 0.45 & 2.65 & $0.20-0.50$ & $0.6-1.5$ \\
& 0.31 & 8 & 2.3 & 2.65 & $0.40-0.65$ & $1.7-3.7$ \\
& 0.31 & 9 & 0.45 & 2.65 & $0.30-0.60$ & $1.2-2.5$ \\
& 0.3 & 9 & 3.55 & 2.65 & $0.60-0.90$ & $1.0-4.2$ \\
\hline
\end{tabular}

$<<1$. The banks are assumed to be non-erodible and the bottom sediment to be non-cohesive. (See the sketch in Figure 3.) The flow is described using the mass balance and the depth-averaged St. Venant equations:

$$
\begin{aligned}
& \frac{\partial}{\partial \mathrm{t}}\left(\zeta-z_{b}\right)+\vec{\nabla} \cdot\left(\vec{U}\left(\zeta+h_{*}-z_{b}\right)\right)=0 \\
& \frac{\partial U}{\partial t}+\vec{U} \cdot \vec{\nabla} \vec{U}+g \vec{\nabla} \zeta=\vec{\psi}
\end{aligned}
$$

in which $\vec{\psi}$ represents the forcing and friction mechanism:

$$
\left.\left.\vec{\psi}=\left(\left\{-C_{\mathrm{d}} \frac{v \sqrt{u^{2}+v^{2}}}{\zeta-z_{b}+h_{*}}\right\}\right)+i_{b} g\right\},\left\{-C_{d} \frac{v \sqrt{u^{2}+v^{2}}}{\zeta-z_{b}+h_{*}}\right\}\right)
$$

Here $g$ is the acceleration due to gravity and $z_{b}$ is the elevation of the disturbed bed relative to the undisturbed bed. $\zeta$ is the elevation of the disturbed free surface, with respect to the undisturbed

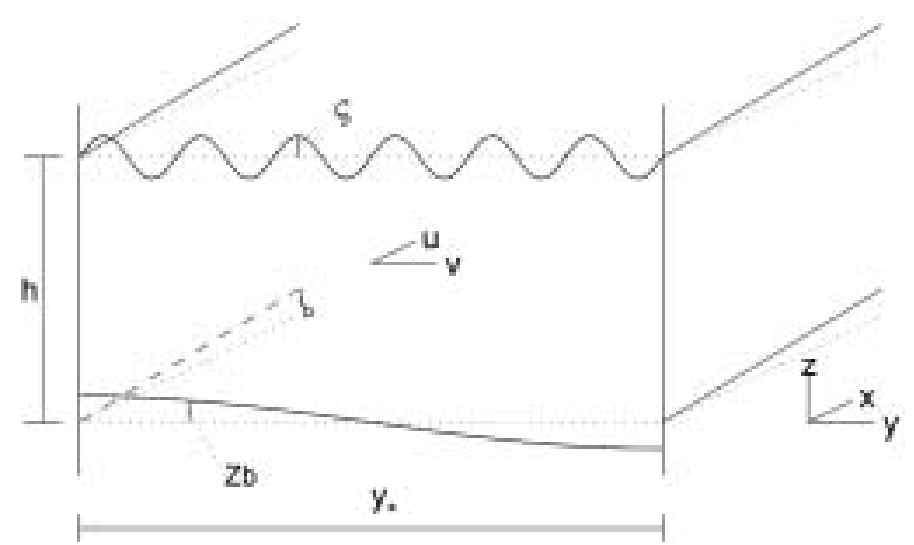

Fig. 3. Sketch explaining the definitions in the model (after Schielen et al. [14]) 
water level $h_{*} \cdot \vec{U}=(u, v)$ is the flow velocity vector in $x$ and $y$ direction and the operator $\vec{\nabla}$ is defined as

$$
\left(\frac{\partial}{\partial x}, \frac{\partial}{\partial y}\right) \text {. }
$$

Finally,

$$
C_{d}=\frac{g}{C_{z}^{2}}
$$

is the drag coefficient, in which $\mathrm{C}_{\mathrm{z}}$ is the Chezy coefficient. The sediment is transported as bed-load, which is modelled as:

$$
\vec{S}=\sigma|\vec{U}|^{b}\left(\frac{\vec{U}}{|\vec{U}|}-\gamma \vec{\nabla} z_{b}\right)
$$

The sediment mass balance yields:

$$
\frac{\partial z_{b}}{\partial t}+\vec{\nabla} \cdot \vec{S}=0
$$

where $\vec{S}=\left(\mathrm{S}_{\mathrm{x}}, \mathrm{S}_{\mathrm{y}}\right)$ is the sediment transport, in volume per unit of time, in $x$ and $y$-direction. Furthermore, the non-linearity of the sediment transport with respect to the flow $b$ is limited to $2<b<$ 7. The downhill preference of the sediment transport is accounted for by $\gamma>0$. Both parameters are dimensionless. The sediment transport proportionality parameter $\sigma$ depends on the sediment properties and includes the effect of the porosity of the bed.

To close the model at both side walls $\left(y=0, y=\mathrm{y}_{*}\right)$ boundary conditions have to be defined:

$$
\left.v\right|_{y=0}=0,\left.\quad S_{y}\right|_{y=0}=0,\left.\quad v\right|_{y_{*}}=0,\left.\quad S_{y}\right|_{y_{*}}=0
$$

The model defined by the Equations (2),(3),(6),(7) and the boundary conditions (8) allows for a solution, describing uniform flow over a plane sloping bed:

$$
\left(u_{0}, v_{0}, \zeta_{0}, z_{\mathrm{b} 0}\right)=\left(u_{*}, 0,0,0\right)
$$

(Note that $\mathrm{u}_{*}$ is the uniform flow velocity, not the shear velocity.)

\subsection{Stability analysis}

The starting point of every stability analysis should be a physically relevant, exact solution to the mathematical model. Equation (9) represents such a basic solution. This basic state is perturbed by small-amplitude, periodic bed waves:

$$
\phi=\phi_{0}+\int_{0}^{\infty} \varepsilon e^{i k x+\omega t} f_{k}(y) d k
$$

in which $\phi=\left(u, v, \zeta, z_{b}\right)$ and $\phi_{0}$ denotes the basic state given by Equation (9). The complex morphological wave frequency $\omega\left(k, R, b, \gamma, C_{d}\right)$ is related to the morphological wave number $k$, the width-to-depth ratio

$$
R=\frac{y_{*}}{h_{*}}
$$

and the model parameters $C_{d}, b$ and $\gamma$. If the growth rate (given by the real part of $\omega$ ) is negative, the basic state is stable: the perturbations decrease in amplitude and disappear. Under other physical circumstances, the basic state is unstable: the disturbances start to grow, forming a rhythmic pattern.

Schielen et al. [1] substituted the perturbation (10) into the model Equations (3)-(7), linearised for small perturbations. Thus, they found a relationship between the complex wave frequency and the wave number. Using this relationship, one can determine whether the basic state is stable or unstable (see Figure 4). As can be seen in Figure 4, a whole range of waves has positive growth rates. However, for each condition the alternate bars have only one wavelength. More information is needed to find this wavelength. To derive information about the shape and the behaviour of the bars, Schielen et al. [14] had to consider the non-linear terms. In agreement with Colombini et al. [4], they assumed a weakly nonlinear regime:

$$
\begin{aligned}
& R=R_{\mathrm{c}}\left(1+\varepsilon^{2} r\right) \\
& k=k_{c}+k_{1} \varepsilon
\end{aligned}
$$

with $\varepsilon<<1$ and some unknown $-1<k_{1}<1 .\left(R_{c}, k_{c}\right)$ is the first combination of the width-to-depth ratio $R$ and the wave number $k$ to give an unstable basic state for increasing $R$ (the lowest point above the neutral curve in Figure 4). Assumption (11) means, that the width-to-depth ratio is just large enough to give growing perturbations.

This approach led to the following wave [14]:

$$
z_{b}(x, y, t)=h_{*} \varepsilon A(\chi, \tau) e^{i k_{c} x^{\prime}+\omega_{c} t^{\prime}} \cos \left(\pi y^{\prime}\right)+\text { h.o.t }+ \text { c.c. }
$$

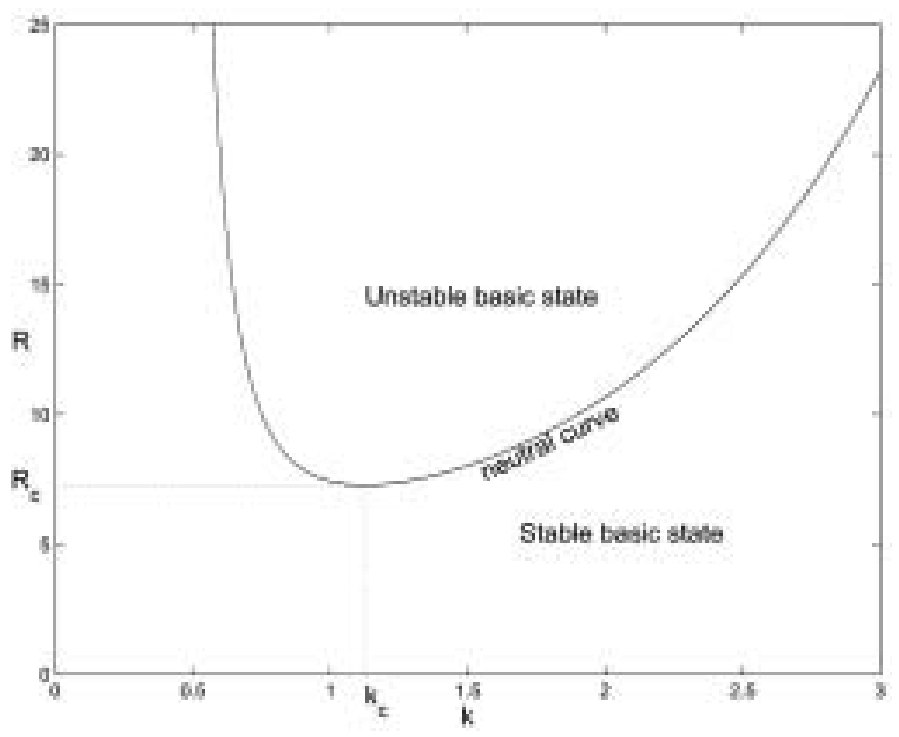

Fig. 4. Example of a neutral curve, dividing the region with a stable basic state from the region with an unstable basic state. $\mathrm{R}$ is the width-to-depth ratio; $\mathrm{k}$ gives the wave number of the perturbations. 
in which $\varepsilon$ is defined by Equation (11). $k_{\mathrm{c}}$ and $\omega_{\mathrm{c}}$ are the critical wave number and the critical frequency, respectively. Furthermore, $\left(x^{\prime}, y^{\prime}, t^{\prime}\right)$ are the dimensionless co-ordinates

$\left(\frac{x}{y_{*}}, \frac{y}{y_{*}}, t \frac{\sigma u^{b}}{y_{*} h_{*}}\right)$

The cosine in Equation (13)models the alternation of the crest, h.o.t. denotes the higher order terms $\left(\mathrm{O}\left(\varepsilon^{2}\right)\right)$ and c.c. means the complex conjugates. The amplitude $A(\xi, \tau)$ follows from:

$$
\frac{\partial A}{\partial \tau}+\alpha_{1} A+\alpha_{2} \frac{\partial^{2} A}{\partial \xi^{2}}+\alpha_{3}|A|^{2} A=0
$$

This equation is known as the Ginzburg-Landau equation. Here, $\tau$ is the morphological time and $\xi$ is the morphological co-ordinate in a frame moving with the group velocity $v_{b}$ of the bars:

$$
\begin{aligned}
& \tau=\varepsilon^{2} t^{\prime} \\
& \chi=\varepsilon\left(x^{\prime}+v_{k} t^{\prime}\right)
\end{aligned}
$$

The parameters $\alpha_{i}(i=1,2,3)$ in Equation (14) are complex functions of the drag coefficient $C_{\mathrm{d}}$ and the transport parameters $b$ and $\gamma$ and $\sigma$.

\subsection{Model parameters}

To calculate the wave length and wave height using Equation (13), we need values for $C_{\mathrm{d}}, b$ and $\gamma$. Unlike small bedforms, alternate bars do not influence the bed roughness. (During the experiments the depth $h_{*}$, slope $i_{\mathrm{b}}$ and flow velocity $u_{*}$ do not change significantly, while the alternate bars develop.) Therefore, the drag coefficient $C_{\mathrm{d}}$ can be estimated using Equations (1) and (5):

$$
C_{d}=\frac{g i_{b} h_{*}}{u_{*}^{2}}
$$

Accurate values of exponent $b$ are unknown. However, using Chezy's law:

$$
\theta=\frac{\left|u_{*}\right|^{2}}{C_{z}\left(\frac{\rho_{s}}{\rho}-1\right) d_{50}}
$$

(where $\theta$ is the shields stress) and the commonly used formula by Meyer-Peter and Müller [11], describing transport of sediment:

$$
S=13.3\left(\mu \theta-\theta_{\mathrm{c}}\right)^{3 / 2} \sqrt{\left(\frac{\rho_{\mathrm{s}}}{\rho}-1\right) g d_{50}^{3}}
$$

one can derive that:

$$
b \approx \frac{3}{1-\frac{\theta_{c}}{\mu \theta}}
$$

where $\theta_{c}$ is the critical Shields parameter and $\mu$ the bed-form or efficiency factor.

Finally, the slope coefficient $\gamma$ can be estimated using the relation derived by Sekine and Parker [15]:

$$
\gamma=0.75\left(\frac{\theta_{c}}{\mu \theta}\right)^{1 / 4}
$$

\section{Comparison between theoretical and experimental results}

Given the conditions of the experiments described in section 2, the model of Schielen et al. [14] predicts the wave length and wave height of alternate bars. These predictions are compared with the measured values. Figure 5(a) and Figure 6(a) show the results of the wavelength and wave height predictions respectively.

The model predicts the characteristics of the larger bars accurately, but the predictions of the smaller sized bars are not satisfactory. These smaller bars are measured in the small-scale flume experiments. Figure 7 shows, that the errors in the predictions are related to the parameter $R \sqrt{R e}$. Here $R e=\frac{h_{*} u_{*}}{v}$ is the Reynolds number, with $v$ the kinematic viscosity. More generally, used parameters, like the Reynolds number or the Froude number, give no relation with the errors.

The relation to the parameter $R \sqrt{R e}$ can be explained from the assumptions in the model of Schielen et al. [14]. They assume that, in zeroth order $(\mathrm{O}(1))$, the dissipation is small compared to the advection: $\mathrm{R}_{\mathrm{e}}>>1$. In first order i.e. $\mathrm{O}(\varepsilon)$ they assume that the total dissipation is dominated by the vertical dissipation: the width-to-depth ratio $R>1$. In the model, the effect of the horizontal dissipation is neglected. This assumption is valid if $R \sqrt{R e} \gg 1$ Horizontal dissipation distributes the friction from the boundaries to the inner domain. The horizontal dissipation distributes the friction generated at the side-banks, while the vertical dissipation distributes the friction generated at the bed. Using the reasoning in the above, Schielen et al. [14] neglect the boundary effects near the banks.

Due to the horizontal dissipation of the friction with the side
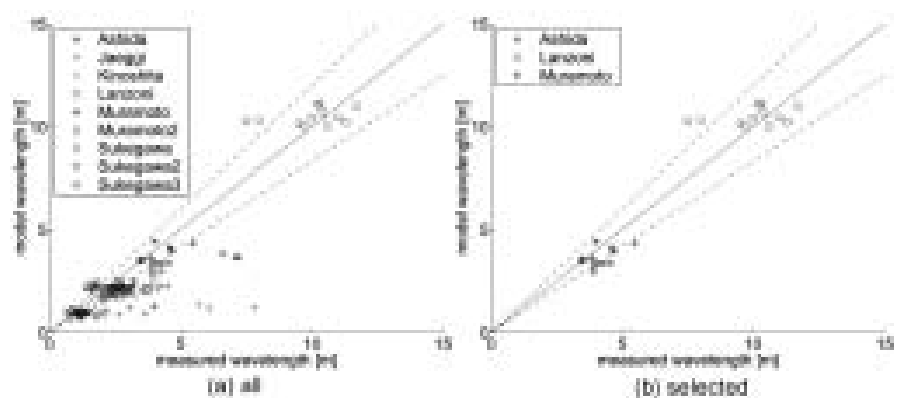

Fig. 5. The predicted wave length plotted against the measured values (a) for all experiments and (b) for the experiments with $R \sqrt{R e}>$ 2000. The dotted lines show the $20 \%$ error boundaries. 

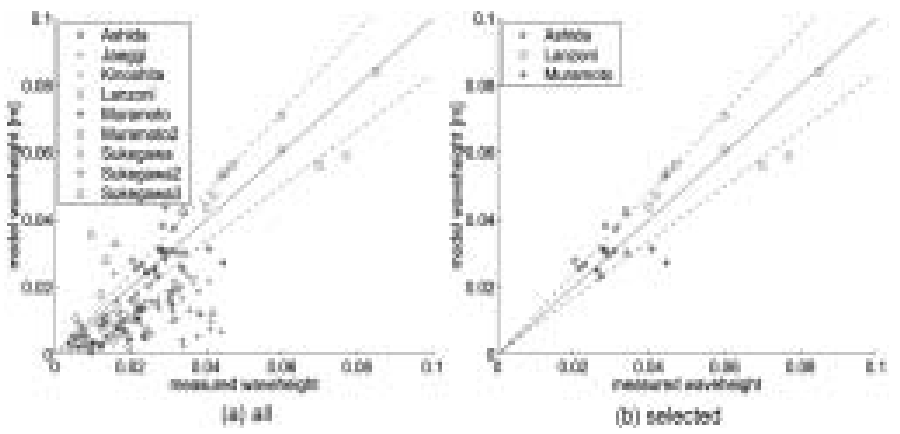

Fig. 6. The predicted wave height plotted against the measured values (a) for all experiments and (b) for the experiments with $R \sqrt{R e}>$ 2000. The dotted lines show the $20 \%$ error boundaries.

walls, the flow velocity in the boundary layer near these walls is smaller thanthe mean velocity. The model of Schielen et al. [14] assumes uniform flow velocities over the channel width. Consequently, the model locally underestimates the drag coefficient. Finally, in the model the bar height is proportional to the drag coefficient. Thus, the bar height, which is measured near the walls, is underestimated. Apparently, the effect of the boundary layer is significant to the bar height if $R \sqrt{R e}<2 * 10^{3}$ (Figure 7) This value has to be regarded as an empirical result. So far, we can not derive this number from theoretical arguments.

In agreement with Colombini et al. [4], the authors assume that this is an artefact of the small channel width in the experiments. The dynamics in the small flume experiments differ significantly from the dynamics in the field, where in general $R \sqrt{R e}>2 * 10^{3}$. Therefore, one has to consider, whether the results of small-scale flume experiments are useful in case of morphodynamic problems.

If $R \sqrt{R e}>2 * 10^{3}$, the model estimates both wave length and wave height accurately, as can be seen in Figure 5(b) and Figure 6(b). (The standard deviation is of the same order as the measurement noise, which is merely caused by small bed forms. Even in the

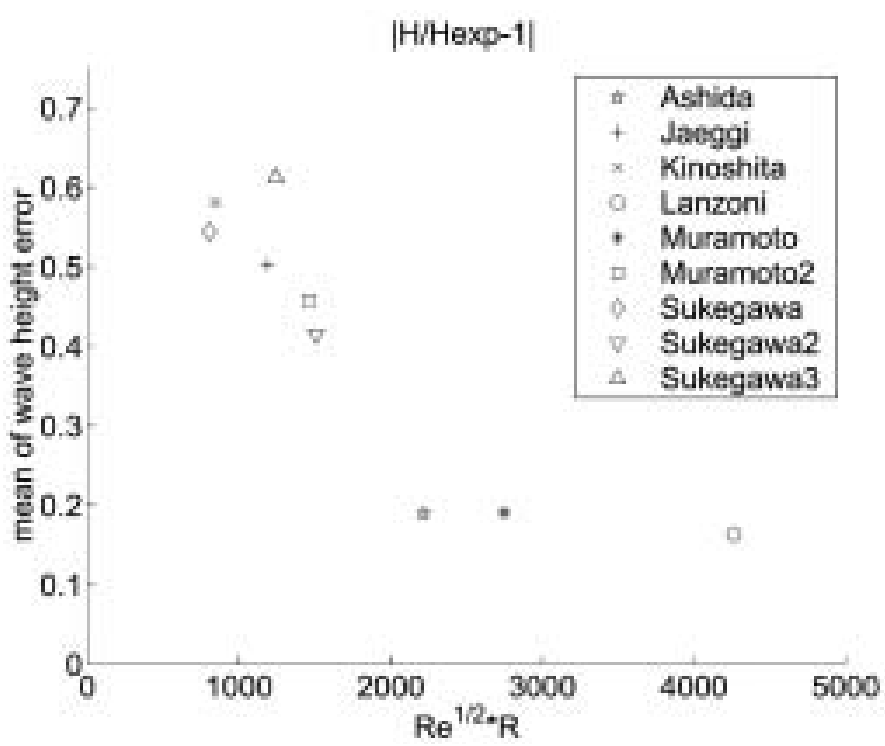

Fig. 7. Mean of the absolute errors in the wave height predictions as a function of the dimensionless parameter $R \sqrt{R e}$, exp denotes the measured values. strong non-linear cases, in which the width-to-depth ratios are large compared to the critical values, the results are good. This is striking, since the model is based on the assumption that the width-to-depth ratio is close to its critical value. This means that the model is useful outside the theoretical restrictions.

In the Lanzoni experiments, the predicted wave heights are high compared to the measurements. However, the errors are small and may be caused by the filter method used by Lanzoni. As stated in section 2.1 the moving-average method results in low estimates of the wave height.

In the experiments with larger flumes, the predicted wavelengths coincide with the measured values. Most errors are less than $10 \%$ of the values, which is small compared to the measurement noise. The two outliers in the Lanzoni experiments (P2403, P0404) can be explained (see [8]). In one case, the power spectrum is double peaked. The wavelength of the peak that is disregarded by Lanzoni [9] coincides with the predicted values. In the other case, there is no clear alternate bar pattern. The outliers in the smallscale flume experiments are related to a high Froude number $\left(\mathrm{F}_{\mathrm{r}}\right.$ $>1$ ). Schielen et al. [14] assume a Froude number $<1$.

The model predicts the wavelength and height of the alternate bars equally well in experiments with graded sediment as in experiments with uniform sediment. Apparently, the grading of sediment has no significant influence on the behaviour of the alternate bars. Therefore, it can be concluded, that the sediment transport parameters capture the effect of the sediment composition sufficiently.

\section{Conclusions}

The model of Schielen et al. [14] predicts the wavelength and height of alternate bars accurately in flume experiments if $R \sqrt{R e}>$ $2 * 10^{3}$. For these experiments, the errors can be considered as white noise. The standard deviation is of the same order as the measurement noise, which is merely caused by small-scale bed forms, such as dunes and ripples.

There are no differences between the results in the experiments using uniform sediment [9] and the experiments using graded sediment [10]. The model parameters capture the effects of the sediment composition sufficiently.

However, if $R \sqrt{R e}<2 * 10^{3}$, the measured heights are significantly larger than predicted. The model used neglects the dissipation near the side banks. This results in an underestimation of the alternate bar heights. The dynamics in the small-scale flume experiments differ significantly from the dynamics in the field. This questions the usefulness of small flume experiments for morphodynamic problems.

We conclude, that the model predicts the basic characteristics of alternate bars well, even far from critical conditions. This justifies further research into predicting alternate bar behaviour, using the model of Schielen et al. [14] in combination with data-assimilation.

\section{Acknowledgement}

The authors thank the Dutch Organisation for Scientific Research 
(NWO) for funding this work through the 'Non Linear Systems' priority program (under project number 620-61-349). It is linked to the PACE-project in the framework of the EU-sponsored Marine Science and Technology Program (MAST III), under contract number MAS3-CT95-0002.

\section{Symbols}

Table 3. List of symbols, subscripts and superscripts

\begin{tabular}{|c|c|c|}
\hline symbol & description & unity \\
\hline A & scaled alternate bar amplitude & {$[-]$} \\
\hline $\mathrm{C}_{\mathrm{d}}$ & drag coefficient & {$[-]$} \\
\hline $\mathrm{C}_{2}$ & Chezy coefficient & {$\left[\mathrm{m}^{1 / 2} / \mathrm{s}\right]$} \\
\hline $\mathrm{F}_{\mathrm{r}}$ & Froude number & {$[-]$} \\
\hline $\mathrm{H}_{\mathrm{b}}^{\mathrm{r}}$ & alternate bar height & [m] \\
\hline $\mathrm{L}_{\mathrm{b}}$ & alternate bar length & [m] \\
\hline $\mathrm{Q}$ & water flux & {$\left[\mathrm{m}^{3} / \mathrm{s}\right]$} \\
\hline $\mathrm{R}$ & width-to-depth ratio & {$[-]$} \\
\hline $\mathrm{R}_{\mathrm{e}}$ & Reynolds number & {$[-]$} \\
\hline $\mathrm{S}$ & sediment transport vector & {$\left[\mathrm{m}^{3 /} \mathrm{s}\right]$} \\
\hline $\mathrm{T}$ & duration of experiment & {$[\mathrm{s}]$} \\
\hline $\mathrm{U}$ & flow velocity vector & {$[\mathrm{m} / \mathrm{s}]$} \\
\hline $\mathrm{b}$ & on linearity of sediment transport & {$[-]$} \\
\hline d & grain diameter & {$[\mu \mathrm{m}]$} \\
\hline $\mathrm{g}$ & gravity constant & {$\left[\mathrm{m} / \mathrm{s}^{2}\right]$} \\
\hline $\mathrm{h}$ & water depth & {$[\mathrm{m}]$} \\
\hline $\mathrm{i}_{\mathrm{b}}$ & longitudinal free surface slope & {$[-]$} \\
\hline $\mathrm{k}$ & morphological wave number & {$[-]$} \\
\hline $\mathrm{t}$ & time & [s] \\
\hline $\mathrm{u}, \mathrm{v}$ & longitudinal and transverse flow velocity & {$[\mathrm{m} / \mathrm{s}]$} \\
\hline $\mathrm{x}, \mathrm{y}, \mathrm{z}$ & longitudinal, transverse and vertical position & {$[\mathrm{m}]$} \\
\hline $\mathrm{y}_{*}$ & channel width & [m] \\
\hline $\mathrm{z}_{\mathrm{b}}$ & elevation disturbed bed & {$[\mathrm{m}]$} \\
\hline$\phi$ & State vector of the morphological problem & {$[-]$} \\
\hline$\Psi$ & Forcing and friction term in the flow equations & {$[-]$} \\
\hline$\alpha_{1}$ & exponential amplitude growth coefficient & {$[-]$} \\
\hline$\alpha_{2}$ & horizontal amplitude variation coefficient & {$[-]$} \\
\hline$\alpha_{3}$ & non-linear amplitude decay coefficient & {$[-]$} \\
\hline$\varepsilon$ & small parameter & {$[-]$} \\
\hline$\gamma$ & downhill preference of sediment transport & {$[-]$} \\
\hline$\dot{\mu}$ & bed form factor & {$[-]$} \\
\hline$v_{\mathrm{b}}$ & group velocity of the alternate bars & {$[-]$} \\
\hline$\psi$ & forcing of the flow & {$\left[\mathrm{m} / \mathrm{s}^{2}\right]$} \\
\hline$\rho$ & density & {$\left[\mathrm{g} / \mathrm{cm}^{3}\right]$} \\
\hline$\sigma$ & sediment transport proportionality & {$[-]$} \\
\hline$\tau$ & morphological time & {$[-]$} \\
\hline$\theta$ & Shields parameter & {$[-]$} \\
\hline$\xi$ & morphological length & {$[-]$} \\
\hline$\zeta$ & elevation disturbed free surface & {$[\mathrm{m}]$} \\
\hline$\omega$ & morphological wave frequency & {$\left[\mathrm{m} / \mathrm{s}^{2}\right]$} \\
\hline \multicolumn{3}{|l|}{ subscripts } \\
\hline 50 & median & \\
\hline 90 & $90 \backslash \%$ is smaller & \\
\hline c & critical value & \\
\hline s & of sediment & \\
\hline s & longitudinal component & \\
\hline y & transversal component & \\
\hline * & average value & \\
\hline 0 & basic solution & \\
\hline & $\mathrm{f}$ the river bed & \\
\hline \multicolumn{3}{|l|}{ superscript } \\
\hline 1 & scaled value & \\
\hline
\end{tabular}

\section{References}

1. Ashida, K. and Shiomi, Y., Study on the hydraulics behaviour of meander in channels, in Disaster Prevention Research Institute Annuals, pp. 457-477, Kyoto University, 1966.

2. Blondeaux, P. and Seminara, G., A unified bar-bend theory of river meanders, Journal of Fluid Mechanics, 157, pp. 449-470, 1985.

3. Colombini, M. and Tubino, M., Finite-amplitude free bars: a fully non-linear spectral solution, in Euromech 262, edited by Soulsby and Bettess, pp. 163-169, Balkema, Rotterdam, 1991.

4. Colombini, M., Seminara, G. and Tubino, M., Finite amplitude alternate bars, , Journal of Fluid Mechanics, 181, pp. 213-232, 1987

5. Fletcher, R., Practical Methods of Optimization, Wiley, 1987.

6. JAEGGI, M., Formation and effects of alternate bars, Journal Hydraulic Division, pp. 1103-1122, ACSE, 110, 1984.

7. Kinoshita, R. Investigation of channel deformation in Ishikari river, Tech. report, Bureau of Resources, Department of Science and Technology, Japan, 1961.

8. KnaApen, M.A.F., Hulscher, S.J.M.H., DE VRIEND, H.J., and van Harten, A., Alternate bar patterns in rivers: Modelling vs. laboratory experiments, in Advances in Hydro-Science and -Engineering, edited by K. Holtz, W. Bechteler, S. Wang and M. Kawahara, ICHE'98, CD-ROM, 1998.

9. LANZONI, S. Experiments on free and forced bar formation in a straight flume. Uniform sediment, research report Q1774, Delft Hydraulics, 1995.

10. LANZONI, S. Experiments on free and forced bar formation in a straight flume. Graded sediment, research report Q1774, Delft Hydraulics, 1997.

11. Meyer-Peter, E. and Müller, R., Formulas for bed-load transport, IAHR, Stockholm, 1948.

12. Muramoto, Y. and Fujita, Y., The classification of mesoscale river bed configuration and the criterion of its formation, Proceedings $22^{\text {nd }}$ Japanese Conference on Hydraulics, pp. 275-282, ISCE, 1978.

13. Oppenheim, A. V. and Schafer, R. W., Discrete-Time Signal Processing, Prentice-Hall, Englewood Cliffs, NJ, 1989.

14. Schielen, R. M. J., Doelman, A., and de Swart, H. E., On the non-linear dynamics of free bars in straight channels, Journal of Fluid Mechanics, 252, pp. 325-356, 1993.

15. Sekine, M. and Parker, G., Bed-load transport on transverse slope, Journal of Hydraulic Engineering, 118, 513-535, 1992.

16. Seminara, G. and Tubino, M., Alternate bars and Meandering: Free, Forced and Mixed Interactions, American Geophysical Union, 1989.

17. Sukegawa, N., Study on meandering of streams in straight channels, Tech. report, Bureau of Resources, Department of Science and Technology, Japan, 1971.

18. Tubino, M., Growth of alternate bars in unsteady flow, Water Resource Research, 27(1), pp. 37-52, 1991. 